\title{
Macronutrient intake induces oxidative and inflammatory stress: potential relevance to atherosclerosis and insulin resistance
}

\author{
Paresh Dandona ${ }^{1,2,3}$, Husam Ghanim ${ }^{1}$, \\ Ajay Chaudhuri ${ }^{1}$, Sandeep Dhindsa ${ }^{1}$ and \\ Sung Soo Kim ${ }^{2}$ \\ ${ }^{1}$ Division of Endocrinology \\ Diabetes and Metabolism \\ State University of New York at Buffalo and \\ Kaleida Health 3 Gates Circle Buffalo, NY 14209 \\ ${ }^{2}$ Department of Biochemistry and Molecular Biology (BK21 project) \\ Medical Research Center for Bioreaction to Reactive Oxygen Species \\ and Biomedical Science Institute \\ School of Medicine, Kyung Hee University \\ Seoul 130-701, Korea \\ ${ }^{3}$ Corresponding author: Tel, 716-887-4523; \\ Fax, 716-887-4773; E-mail, pdandona@ KaleidaHealth.org \\ DOI 10.3858/emm.2010.42.4.033
}

Accepted 4 March 2010

Available Online 4 March 2010

Abbreviations: 13-HODES, 13-hydroxyoctadecadienoic acid; AMI, acute myocardial infarction; AP-1, activator protein-1; BP, blood pressure; CCL-2, CC chemokine ligand 2; CCR-2, CC chemokine receptor 2; $\mathrm{CHD}$, coronary heart disease; $\mathrm{CRP}, \mathrm{C}$-reactive protein; CVD, cardiovascular disease; DART, diet and reinfarction trial; DHA, docosahexaenoic acid; Egr-1, early growth response 1; EPA, eicosapentaenoic acid; GGT, gamma-glutamyl transpeptidase; GISSI, gruppo Italiano per lo studio della sopravvivenza nell'Infarto miocardico; GSK-3 $\beta$, glycogen synthase kinase-3 $\beta$; HFHC, high fat high carbohydrate; HNF, hepatic nuclear factors; ICD, implantable cardioverter-defibrillator; IKK, IKB kinase; IRS-1, insulin receptor substrate 1; IRS-2, insulin receptor substrate 2; JELIS, Japan EPA lipid intervention study; LXR, liver X receptor; MCP-1, monocyte chemoattractant protein-1; MI, myocardial infarction; MMP-2, matrix metalloproteinases 2; MRFIT, multiple risk factor intervention; mTOR, mammalian target of rapamycin; PECAM, platelet endothelial cell adhesion molecule; PGI3, prostacyclin I3; PI3-kinase, phosphoinositide 3-kinase; PPAR, peroxisome proliferator activated receptors; RCTs, randomized controlled trials; ROS, reactive oxygen species; $R R$, relative risk; $R X R$, retinoid $X$ receptors; S-6-K, ribosomal protein S6 kinase; SCFA, short chain fatty acids; SOCS-3, suppressor of cytokine signaling-3; SREBP-1c, sterol regulatory binding protein-1c; TBARS, plasma concentrations of thiobarbituric acid-reactive species; TF, tissue factor; TLR-4, toll-like receptor 4; t-PA, tissue plasminogen activator; VT, ventricular tachycardia

\begin{abstract}
With the global increase in the epidemic of obesity and type 2 diabetes with a concomitant increase in atherosclerotic disease, an investigation into the effects of various macronutrients and food products has become necessary. Such investigation will allow us to better understand the relationship between the intake of various macronutrients and the pathogenesis of mechanisms underlying the regulation of insulin sensitivity and resistance, oxidative stress and inflammation, the regulation of hunger and satiety and atherogenesis. This review covers the first decade of work in this area relating the intake of usual foods and diets to their immediate and long term outcomes. The review also covers the exciting novel area of anti-inflammatory effects of certain foods. Hopefully, a comprehensive understanding of these actions of macronutrients and their long term effects will allow us to formulate food combinations which will lead to healthy eating habits and improvement in our overall health status.
\end{abstract}

Keywords: atherosclerosis; diabetes mellitus, type 2; inflammation; insulin resistance; micronutrients; oxidative stress

\section{Introduction}

The association of obesity with chronic low grade inflammation and insulin resistance is well established (Hotamisligil et al., 1993; Festa et al., 2000). The facts that obesity is the most powerful risk factor for type 2 diabetes and that increased concentrations/expression of inflammatory mediators in the obese predicts the occurrence of future diabetes are also well established (Pradhan et al., 2001). In addition, type 2 diabetes is also known to be associated with chronic inflammation (Pickup et al., 1997). Recent data also demonstrate that inflammatory mediators may interfere with insulin signal transduction (Hotamisligil et al., 1996; Ghanim et al., 2007a). These facts reinforce the importance of inflammation in the pathogenesis of insulin resistance and type 2 diabetes. So, what is the link between these facts and what is the origin 
of this inflammation?

\section{Macronutrient intake, oxidative stress and inflammation}

Since the relationship between obesity and insulin resistance is a dynamic one and weight gain leads to increased resistance and weight loss to a reduction in insulin resistance, it is possible that macronutrient intake may be crucial and central to these relationships. This concept led us to investigate whether macronutrient intake leads to an increase in inflammation and caloric restriction leads to a reduction in inflammation. Since oxidative stress and reactive oxygen species (ROS) generation lead to the activation of redox sensitive pro-inflammatory transcription factors (Woronicz et al., 1997; Wang et al., 1999), we also studied the effect of macronutrient intake and caloric restriction on ROS generation and oxidative stress.

The first demonstration that a macronutrient induces ROS generation was made when it was shown that the intake of glucose by normal subjects leads to an increase in ROS generation by polymorphonuclear (PMN) and mononuclear (MNC) leucocytes (Mohanty et al., 2000). This could be inhibited by diphenyl iodonium, an inhibitor of NADPH oxidase and was measured by chemiluminescence with luminol in the medium. It was, therefore, concluded that this increase in superoxide (ROS) generation was from the leukocyte membrane and that superoxide was released into the extracellular medium. Consistent with this, there was an increase in the expression of p47phox, a key subunit of the enzyme NADPH oxidase which converts molecular $\mathrm{O}_{2}$ into superoxide. A similar effect was also observed with saturated fat (cream) and to a much smaller extent with protein (casein) (Mohanty et al., 2002). Although the magnitude of this effect (area under the curve) was similar for glucose and cream, the peak effect of glucose was at $2 \mathrm{~h}$ with a decline at $3 \mathrm{~h}$. The progression of this effect was slower for cream and there was a persistence of this effect at $3 \mathrm{~h}$ without a significant decline. A high fat high carbohydrate (HFHC) meal induced a similar effect with an increase in ROS generation and an increase in $\mathrm{p} 47^{\text {phox }}$ expression (Aljada et al., 2004b). The other source of ROS following glucose intake is the mitochondrion. Superoxide radicals are generated from the electron transport chain during the metabolism of glucose and other metabolites.

Since, as stated above, several of the pro-inflammatory transcription factors are redox sensitive, and it seemed likely that the stimulation of ROS generation would be associated with the activation of these transcription factors, we investigated them and the genes which would be stimulated by them. NF-kB, activator protein-1 (AP-1) and early growth response 1 (Egr-1) are activated by the intake of glucose; accompanying this activation, there is an increase in the expression of TNF $\alpha$, matrix metalloproteinases 2 (MMP-2), matrix metalloproteinases 9 (MMP-9) and tissue factor (TF) (Aljada et al., 2004a). The activation of NFKB has also been shown by an HFHC meal (Aljada et al., $2004 \mathrm{~b})$. This is achieved through the activation of $\mathrm{I} \kappa \mathrm{B}$ kinase (IKK) and the phosphorylation of $\mathrm{I} \kappa \mathrm{B} \alpha$ $(\mid \kappa B \alpha)$. Since the binding of $I_{\kappa} B \alpha$ to $N F \kappa B$ is required for the prevention of the nuclear translocation of $\mathrm{NFKB}$ and since the phosphorylation of $I_{\kappa} B \alpha$ leads to the dissociation of $I_{\kappa B} \alpha$ from $N F_{\kappa B}$, NF $F_{\kappa B}$ translocates into the nucleus and activates the transcription of pro-inflammatory genes including TNF $\alpha$ (Barnes and Karin, 1997). Similarly, the activation of AP-1 leads to the transcription of MMP-2 and MMP-9 and that of Egr-1 to the transcription of TF. Thus, the intake of glucose leads to oxidative and inflammatory stress and a prothrombotic state. Our more recent work shows that a large HFHC meal induces a more intense and prolonged oxidative and inflammatory stress response in the obese than that in normal weight subjects (Patel et al., 2007). This is consistent with the fact that obesity is a pro-inflammatory state (Ghanim et al., 2004). These data also raise the question whether obesity is also associated with increased oxidative stress.

\section{Increased oxidative stress with obesity and its reversal following caloric restriction and weight loss}

Indeed, human obesity is associated with both inflammatory and oxidative stress. Plasma concentrations of thiobarbituric acid-reactive species (TBARS), 9-hydroxyoctadecadienoic acid (9-HODES) and 13-hydroxyoctadecadienoic acid (13-HODES), and ortho-tyrosine and meta-tyrosine concentrations are elevated in the obese in the fasting state (Dandona et al., 2001a; Ghanim et al., 2004). These indices as well as ROS generation by mononuclear and polymorphonuclears fall dramatically with caloric restriction and weight loss over a relatively short period of two weeks (Dandona et al., 2001b). Plasma concentrations of TNF $\alpha$ and adipose tissue expression of $\mathrm{TNF} \alpha$ are also increased in the obese and tend to decrease with caloric restriction and weight loss (Dandona et al., 1998). These data are further reinforced by the fact that even in normal subjects, a $48 \mathrm{~h}$ fast results in the reduction of ROS generation by $>50 \%$, with a 
reduction of $35 \%$ at $24 \mathrm{~h}$ (Dandona et al., 2001c). This is associated with a parallel reduction in p47phox expression.

\section{Non-inflammatory and anti-inflammatory foods}

In view of these dramatic acute effects of macronutrient intake in inducing oxidative and inflammatory stress and equally impressive effects of caloric restriction and weight loss in reversing it, the question of whether there are some non-inflammatory foods is raised. Three sets of data have been obtained confirming this concept. Firstly, alcohol (300 Calories) does not induce oxidative and inflammatory stress (Dhindsa et al., 2004). Secondly, orange juice (300 Calories) does not induce oxidative and inflammatory stress (Ghanim et al., 2007b). Thirdly, a high fiber and fruit meal based on AHA guidelines does not induce either oxidative or inflammatory stress when compared to an equicaloric HFHC (900 Calorie) meal (Ghanim et al., 2009).

Our most recent data demonstrate that the intake of orange juice with a high fat high carbohydrate meal leads to the total neutralization of the pro-inflammatory effects of the meal (AJCN, in press). In this study, we observed that the concomitant intake of orange with a HFHC meal led to an almost total inhibition of ROS generation, the increase in $\mathrm{NF} \kappa \mathrm{B}$ binding, the increase in MMP-9 concentration and the increase in the expression of several pro-inflammatory genes. Since two major flavonoids contained in orange juice, naringenin and hesperidin, exert a powerful ROS suppressive effect, it is likely that they contribute to this effect (Ghanim et al., 2007b). Thus, it is possible in principle to choose non-inflammatory or anti-inflammatory foods to minimize post-prandial oxidative stress and inflammation. This search must, therefore, continue and include substances like flavonoids to reduce post prandial oxidative and inflammatory stress. Red wine intake with a HFHC meal has also been shown to exert a neutralization of its pro-inflammatory effect.

Ethanol (=300 Calories) administered as vodka has also been shown not to induce ROS generation or an increase in $\mathrm{NF} \kappa \mathrm{B}$ binding (Dhindsa et al., 2004).

\section{Anti-inflammatory micronutrients}

As discovered in our experiments with orange juice, the flavonoids contained in it, naringenin and hesperidin, were shown to exert a powerful inhibition of ROS generation (Ghanim et al., 2007b). Naringenin and hesperidin may thus be potentially be used to prevent post prandial oxidative and inflammatory stress. Our recent work shows that resveratrol also exerts an ROS suppressive and an anti-inflammatory effect. Thus resveratrol could also potentially provide a means for preventing post prandial inflammation. In addition, resveratrol suppresses several pro-inflammatory kinases which interfere with insulin signal transduction (presented at ADA, 2008). It is clear that these compounds need to be investigated extensively for their interesting effects so that scientifically based rational food choices directed at healthy living can be made.

The potent anti-inflammatory effect of Curcumin, the product of turmeric, the yellow Indian spice Curcuma longa is already well recognized (Aggarwal and Harikumar, 2009). Indeed, turmeric has been used for its anti-inflammatory properties in traditional Indian medicine for millennia and curcumin is currently being investigated for several of its potential therapeutic properties. It has been shown to suppress at least two major pro-inflammatory transcription factors, $A P-1$ and $N F \kappa B$. It has also been shown to have some cancer suppressive properties, probably through a contribution from its anti-inflammatory actions.

\section{Inflammation may contribute to insulin and leptin resistance}

Since inflammatory mediators are known to increase the expression and activity of molecules which interfere with insulin signal transduction, we have also investigated whether these molecules increase post prandially (Hotamisligil et al., 1996; Hirosumi et al., 2002). Indeed, the expression of the suppressor of cytokine signaling-3 (SOCS-3) increases significantly after the intake of an HFHC meal (Ghanim et al., 2009). SOCS-3 is known to interfere with insulin signal transduction at the insulin receptor substrate 1 (IRS-1) level by enhancing the ubiquitination of IRS-1 and by decreasing the association of IRS-1 and phosphoinositide 3-kinase (PI3-kinase) essential for the downstream activation of AKT/PKB (Emanuelli et al., 2001; Rui et al., 2002). Since SOCS-3 also interferes with leptin signal transduction, the induction of this molecule post prandially would also account for leptin resistance (Bjorbaek et al., 1999). Thus, post prandial oxidative and inflammatory stress is not only responsible for a potentially atherogenic milieu but also for insulin and leptin resistance. A cumulative action of such meals may lead to persistent increases in the molecules which interfere with insulin and leptin signal transduction. These observations may also explain to some 
extent how excessive and persistent intake of pro-inflammatory meals may lead to concomitant insulin and leptin resistance. It is of interest in this context that a meal rich in fruit and fiber does not induce either oxidative stress or inflammation or an induction of SOCS-3 (Ghanim et al., 2009). In an attempt to evaluate which component of the HFHC meal is responsible for the induction of oxidative stress, endotoxemia, inflammation and an increase in the expression of SOCS-3 and toll-like receptor 4 (TLR-4), it has been shown that saturated fat taken as cream induces these all while glucose induces oxidative stress, inflammation and SOCS-3 but not endotoxemia or an increase in TLR-4 expression. In contrast, an equicaloric orange juice does not induce any of these changes (Deopurkar et al., 2010).

In order to further establish the link between macronutrient intake, inflammation and the pathogenesis of insulin resistance, we need to investigate several major kinases which have been incriminated as interfering factors in insulin signal transduction. These kinases cause serine phosphorylation of IRS-1 and insulin receptor substrate 2 (IRS-2) and thus block the downstream activation of the insulin signal transduction pathway (Gual, et al., 2005; Schenk et al., 2008). These kinases include PKC- $\beta 2$, IKK, glycogen synthase kinase-3 $\beta$ (GSK-3 $\beta)$, ERK, ribosomal protein S6 kinase (S-6-K), JNK, mammalian target of rapamycin (mTOR). Whether their expression or activation increases following macronutrient intake needs to be investigated.

Since insulin exerts a potent anti-inflammatory action (Dandona et al., 2001b), any tendency towards interference with that effect is likely to result in a pro-inflammatory effect which may potentially promote insulin resistance further in parallel with increased atherogenesis. Indeed, our preliminary data show that insulin suppresses the expression of GSK-3 $\beta$, PKC- $\beta 2$, IKK, mTOR and JNK. This would suggest that insulin may be a potent insulin sensitizer and indeed, our data show that this actually occurs within a few hours of a low dose insulin infusion. Thus, for a given rate of insulin infusion, the amount of glucose that has to be infused increases by 50 to $75 \%$ to maintain euglycemia within 3 to $4 \mathrm{~h}$ of initiating the infusion.

\section{Post prandial inflammation, chemokines and the homing of monocytes as macrophages in tissues}

It has been shown that the chemokine, monocyte chemoattractant protein-1 (MCP-1) or CC chemokine ligand 2 (CCL-2), is secreted by the adipose tissue and that it is likely to be a major factor in attracting monocytes to the adipose tissue (Kanda et al., 2006). Its chemoattractant effect is mediated through its receptor on monocytes, CC chemokine receptor 2 (CCR-2) which also binds MCP-2 and eotaxin. Thus, it is important to determine the induction of chemokine and chemokine receptor patterns following the intake of macronutrients.

It is relevant that following the intake of cream, an increase in the expression of platelet endothelial cell adhesion molecule (PECAM) has been demonstrated (preliminary data). PECAM is an adhesion molecule which expressed both by the monocyte and the endothelial cell (Woodfin et al., 2007). It facilitates the trans-endothelial movement of the monocyte and other leucocytes. It thus facilitates the entry of these cells into extracellular spaces including the arterial intima and the adipose tissue.

On the basis of the above data, we can now consider whether diets based on the above principles have shown outcomes consistent with those data. These data have been obtained from observational studies and randomized controlled trials (RCTs).

\section{Diets and their effects on cardiovascular outcomes}

There is evidence of a causal link between dietary factors and coronary heart disease (CHD). A recent study reviewed 223 prospective cohort studies and 66 randomized controlled trials (RCT) conducted since 1950 to evaluate the effect of diet on CHD (Mente et al., 2009). Determination of an association between dietary factors and CHD in cohort studies was made by the Bradford-Hill criteria, which evaluates causality on the basis of strength, consistency, temporality and coherence for each dietary exposure. The evidence from cohort studies was examined for consistency with the findings of randomized trials.

In this comprehensive review, there was evidence to support a protective effect on CHD of intake of nuts (30\% reduction), vegetables $(23 \%$ reduction), monounsaturated fatty acids (20\% reduction), fish (19\% reduction), marine omega 3 fatty acids ( $14 \%$ reduction), folate (32\% reduction), whole grains (19\% reduction), dietary vitamins $E$ and C (20-23\% reduction), beta carotene (27\% reduction), alcohol (29 to $31 \%$ reduction), fruits (20\% reduction) and fiber (22\% reduction). Among diets, the Mediterranean [37\% reduction] (higher intake of vegetables, legumes, fruits, nuts, whole grain, cheese or yoghurt, fish and monounsaturated relative to saturated fatty acids) and "prudent" 
[27\% reduction] (high intake of vegetables, fruit, legumes, whole grains, fish and other seafood) diets had a beneficial effect on CHD. A harmful effect of trans-fatty acids ( $32 \%$ increase), foods with a high glycemic index or load (32\% increase) and a western dietary pattern [55\% increase] (high intake of processed meat, red meat, butter, high fat dairy products, eggs and refined grains) on CHD was also substantiated by this analysis. Intake of saturated, polyunsaturated fatty acids and total fat, alpha-linolenic acid, meat, eggs and milk were not associated with any significant effect on CHD.

The evidence of causality on the basis of cohort studies was supported by a significant beneficial effect on CHD outcome in RCTs for the Mediterranean diet, and intake of omega 3 fatty acids (see below). The benefits of supplementary folate, beta carotene, Vitamin $\mathrm{E}$ and $\mathrm{C}$ in cohort studies were not replicated in RCT's. Other diets or nutrients shown to have a benefit or harm in cohort studies have not been evaluated in RCTs.

\section{Mediterranean diets}

The Lyon Heart Study demonstrated that the intake of the Mediterranean diet led to a marked reduction in fatal and non-fatal myocardial infarction and the combined outcome of those two and unstable angina, stroke and pulmonary embolism (de Lorgeril et al., 1994). There was a reduction in these events by two thirds. Significant beneficial effect of the diet was observed as early as 27 months and was maintained at 44 months.

\section{The intake of fish and fish oil}

Intake of fish and fish oil has been shown to have beneficial effects on CHD. Fish and fish oil contain long chain omega 3 fatty acids, eicosapentaenoic acid (EPA) and docosahexaenoic acid (DHA). These omega 3 fatty acids lower VLDL triglycerides and reduce thrombotic risk by decreasing platelet adhesiveness and increasing bleeding time (Phillipson et al., 1985; Holub, 1988; Harris et al., 1991; Knapp, 1997). They have also been shown to reduce heart rate, blood pressure, and the vasoconstrictive response to angiotensin II (Kenny et al., 1992; Morris et al., 1993; Mozaffarian et al., 2005). EPA and DHA may also have anti-inflammatory effects as they counter the effect of eicosanoids produced from omega 6 polyunsaturated fatty acids (James et al., 2000). EPA and DHA reduce formation of arachidonic acid by inhibiting phopsholipase A2 (Martin, 1998). They also compete for lipoxygenase and cycloxygenase (COX), thereby decreasing pro-inflamma- tory type 2 eicosanoids and type -4 leukotrienes and increasing formation of prostaglandin E3 (PGE3), prostacyclin I3 (PGI3) and thrombxane A2 (Knapp, 1997; James et al., 2000). Oxygenated metabolites of EPA and DHA formed by cyclooxygenase-2 (COX-2) are called resolvins $E$ and $D$ and these oppose the effect of inflammatory prostaglandins (Serhan et al., 2008). EPA and DHA may also inhibit the activation of toll like receptors 2 and 4 , which are involved in inducing inflammation by activating NFKB (Lee et al., 2004).

Fish consumption has been shown to be related inversely to cardiovascular events in the Nurses' Health Study in a most impressive fashion such that in the highest tertile of fish eaters the rate of cardiovascular events was approximately $45 \%$ lower largely due to a reduction in CHD deaths and the incidence of non fatal acute myocardial infarction (Hu et al., 2002). The intake of fish and $\omega-3$ fatty acids leads to a reduction in thrombotic and thrombo-embolic stroke also shown in the Nurses' Health Study. Compared to subjects eating fish < once/week, patients eating fish once /week had a reduction of relative risk (RR) for stroke to 0.76 and those eating fish between 2 to 4 times a week had a reduction of $R R$ to 0.48 . These rates of reduction are similar to those for acute myocardial infarction (AMI). These effects are consistent with the findings of other large cohort studies including the multiple risk factor intervention (MRFIT) trial, the Honolulu Heart Program and the US Physicians Health study (Dolecek, 1992; Rodriguez et al., 1996; Albert et al., 1998).

Randomized Controlled clinical trials have shown a beneficial effect of fish consumption twice a week or fish oil supplementation at doses of 0.85 grams/day to 5.4 grams/day in primary and secondary prevention of CHD (Jenkins et al., 2008). In the DART (Diet and Reinfarction Trial) study, fish intake or fish oil supplementation reduced mortality by $29 \%$ in subjects post myocardial infarction (MI) (Burr et al., 1989). In the Gruppo Italiano per lo Studio della Sopravvivenza nell'Infarto Miocardico (GISSI) study consumption of 850-882 $\mathrm{mg}$ of EPA and DHA daily for $3.5 \mathrm{yr}$ post $\mathrm{MI}$ was shown to reduce the incidence of AMI, reduce CVD mortality by $30 \%$ and decrease sudden cardiac death by $45 \%$. (Gruppo Italiano per lo Studio della Sopravvivenza nell'Infarto miocardico, 1999) More recently, in the Japan EPA Lipid Intervention study (JELIS), $1,800 \mathrm{mg}$ of EPA reduced major coronary events by $19 \%$ and incidence of unstable angina by $29 \%$ (Yokoyama et al., 2007). Fish oil has also been shown to have anti-arrhythmic effects through inhibition of sodium and L-type calcium channels. In prospective cohort studies and randomized 
controlled trials fish oil consumption and supplementation has been shown to reduce atrial fibrillation, ventricular tachycardia and ventricular fibrillation (Jenkins et al., 2008). However, there is also a suggestion of harm in certain subgroups of cardiac patients, notably those with a history of ventricular tachycardia (VT) and heart failure who require implantable cardioverter-defibrillator (ICD) and are not on anti-arrhythmic drugs and caution is advised about recommending fish oil supplementation in these patients until further studies are completed (Brouwer et al., 2009).

EPA and DHA have also been shown to reduce insulin resistance in animal studies and in some human studies in normal weight and obese individuals (Fedor and Kelley, 2009). As inflammation is one of the major factors that lead to the development of insulin resistance, one of the mechanisms by which omega 3 fatty acids may reduce insulin resistance is through their anti-inflammatory effects. EPA and DHA have also been shown to increase leptin and adiponectin expression and secretion in animal studies. The omega 3 fatty acids are also known to regulate the expression of a number of transcription factors including peroxisome proliferator activated receptors (PPAR), sterol regulatory binding protein-1c (SREBP-1C), hepatic nuclear factors $(H N F)$, retinoid $X$ receptors $(R X R)$ and liver $X$ receptor (LXR) (Fedor and Kelley, 2009). Studies have shown that EPA and DHA may reduce in insulin resistance through the activation of peroxisome proliferator-activated receptor alpha (PPAR $\alpha)$ and peroxisome proliferator-activated receptor gamma (PPAR $\gamma$ ) and suppression of SREBP-1c.

\section{The intake of fiber}

Dietary fibers are classified as soluble, that are fermented in the colon and insoluble, that have bulking action but are fermented only to a limited extent in the colon. Major dietary fiber sources are whole-grain foods, vegetables, fruits, legumes and nuts. Average recommended dietary fiber intake is approximately 28 grams/day for adult women and 36 grams/day for adult men (Anderson et al., 2009).

Increased dietary fiber intake has been shown to reduce the risk of $\mathrm{CHD}$ by $29 \%$, stroke by $26 \%$, diabetes by $19 \%$ and obesity by $30 \%$ in cohort studies (Liu et al., 1999; Montonen et al., 2003; Steffen et al., 2003; Lairon et al., 2005). Fiber intake also improves lipid concentrations, lowers blood pressure, improves blood glucose in diabetes and helps with weight loss (Brown et al., 1999; Keenan et al., 2002; Anderson et al., 2004).

Soluble fibers have significant hypocholeste- rolemic effects and can reduce LDL cholesterol by $5.5 \%$ to $13 \%$ from baseline. They do not have any effect on HDL cholesterol or triglycerides (Brown et al., 1999). Proposed mechanisms for the hypocholestrolemic effects of fiber include the binding of bile acids in the small intestine, thus increasing their excretion in the feces (Kirby et al., 1981). Fermentation of fibers in the small intestine also promotes the growth of bifidobacteria which produce short chain fatty acids (SCFA) and this may inhibit cholesterol synthesis (Wright et al., 1990). Fiber intake has also been shown to reduce systolic blood pressure (BP) by $1.1 \mathrm{~mm} \mathrm{Hg}$ and diastolic BP by $1.2 \mathrm{~mm} \mathrm{Hg}$ (Streppel et al., 2005). These effects are greater in hypertensive subjects with a reduction of $6 \mathrm{~mm} \mathrm{Hg}$ in systolic and $4.2 \mathrm{~mm}$ $\mathrm{Hg}$ in diastolic BP (Whelton et al., 2005).

Intake of fiber is also associated with a reduction in the incidence of diabetes. In the Finnish Diabetes prevention study, subjects with the highest level of fiber consumption had a $62 \%$ reduction in progression from prediabetes to diabetes over a $4.1 \mathrm{yr}$ period compared to those with the lowest fiber intake (Lindstrom et al., 2006). In this study, increase in fiber intake was associated with a reduction in C-reactive protein (CRP) and IL-6, even after adjustment for change in BMI. In non-diabetic subjects, increased fiber intake is associated with an improvement in fasting glucose, insulin and insulin sensitivity (Vuksan et al., 2000). In diabetic subjects, increasing fiber intake is associated with an improvement in fasting and post prandial glucose and overall glycemic control (Anderson et al., 1999). This may be secondary to the anti-inflammatory effects of fiber intake. In a recent study, low dietary fiber intake $(<20$ gram/day) was associated with a $47 \%$ increased risk of diabetes (Wannamethee et al., 2009). Dietary fiber was inversely associated with CRP, interleukin-6, tissue plasminogen activator (t-PA) and gamma-glutamyl transpeptidase (GGT) and adjustment for these markers attenuated the increased risk of diabetes with low fiber intake.

Fiber intake is inversely correlated with weight gain and obesity prevalence. Weight loss of $2 \%$ to $4.9 \%$ of baseline body weight have been seen in short term trials with fiber supplements (Anderson et al., 2009). Intake of fiber may increase satiety by delaying gastric emptying and by increasing gut hormones which increase satiety.

\section{Conclusion}

It is clear that macronutrient intake induces oxidative and inflammatory stress especially when it is 
rich in saturated fat and refined carbohydrates. On the other hand, a meal rich in fiber and containing fruit does not induce either oxidative stress or inflammation. Associated with the induction of inflammation is the increase in the expression of SOCS-3, a mediator of insulin resistance through interference with insulin signal transduction at the IRS-1 level. Post-prandial inflammation following such meals is thus is a potential mediator of atherogenesis and insulin resistance. The fact that diets rich in fiber and fruit are associated with protection from diabetes and atherosclerotic complications in prospective trials is consistent with our observations that such meals do not cause oxidative stress or inflammation. Furthermore our most recent data show that orange juice may actually neutralize inflammation induced by the HFHC meal. This intriguing observation leads one to ask the question whether the combination of anti-inflammatory meals/foods would render the latter safer. These issues need further investigation and eventual incorporation into our life style and eating habits.

\section{Acknowledgements}

This work was supported by grants from the National Institutes of Health and the American Diabetes Association to $\mathrm{P}$ Dandona and the Korea Science and Engineering Foundation grant to SS Kim by the Korea government (No. 20090091346).

\section{References}

Aggarwal BB, Harikumar KB. Potential therapeutic effects of curcumin, the anti-inflammatory agent, against neurodegenerative, cardiovascular, pulmonary, metabolic, autoimmune and neoplastic diseases. Int $\mathrm{J}$ Biochem Cell Biol 2009;41:40-59

Albert CM, Hennekens CH, O'Donnell CJ, Ajani UA, Carey VJ, Willett WC, Ruskin JN, Manson JE. Fish consumption and risk of sudden cardiac death. JAMA 1998;279:23-8

Aljada A, Ghanim H, Mohanty P, Syed T, Bandyopadhyay A, Dandona P. Glucose intake induces an increase in activator protein 1 and early growth response 1 binding activities, in the expression of tissue factor and matrix metalloproteinase in mononuclear cells, and in plasma tissue factor and matrix metalloproteinase concentrations. Am J Clin Nutr 2004a;80: 51-7

Aljada A, Mohanty P, Ghanim H, Abdo T, Tripathy D, Chaudhuri $A$, Dandona $P$. Increase in intranuclear nuclear factor kappaB and decrease in inhibitor kappaB in mononuclear cells after a mixed meal: evidence for a proinflammatory effect. Am J Clin Nutr 2004b;79:682-90

Anderson JW, Allgood LD, Turner J, Oeltgen PR, Daggy BP. Effects of psyllium on glucose and serum lipid responses in men with type 2 diabetes and hypercholesterolemia. Am J Clin Nutr 1999;70:466-73

Anderson JW, Randles KM, Kendall CW, Jenkins DJ. Carbohydrate and fiber recommendations for individuals with diabetes: a quantitative assessment and meta-analysis of the evidence. J Am Coll Nutr 2004;23:5-17

Anderson JW, Baird P, Davis RH Jr, Ferreri S, Knudtson M, Koraym A, Waters V, Williams CL. Health benefits of dietary fiber. Nutr Rev 2009;67:188-205

Barnes PJ, Karin M. Nuclear factor-kB: a pivotal transcription factor in chronic inflammatory diseases. $\mathrm{N}$ Engl $\mathrm{J}$ Med 1997;336:1066-71

Bjorbaek C, El-Haschimi K, Frantz JD, Flier JS. The role of SOCS-3 in leptin signaling and leptin resistance. J Biol Chem 1999;274:30059-65

Brouwer IA, Raitt MH, Dullemeijer C, Kraemer DF, Zock PL, Morris C, Katan MB, Connor WE, Camm JA, Schouten EG, McAnulty J. Effect of fish oil on ventricular tachyarrhythmia in three studies in patients with implantable cardioverter defibrillators. Eur Heart J 2009;30:820-6

Brown L, Rosner B, Willett WW, Sacks FM. Cholesterol-lowering effects of dietary fiber: a meta-analysis. Am J Clin Nutr 1999;69:30-42

Burr ML, Fehily AM, Gilbert JF, Rogers S, Holliday RM, Sweetnam PM, Elwood PC, Deadman NM. Effects of changes in fat, fish, and fibre intakes on death and myocardial reinfarction: diet and reinfarction trial (DART). Lancet 1989;2:757-61

Dandona P, Weinstock R, Thusu K, Abdel-Rahman E, Aljada A, Wadden T. Tumor necrosis factor- $\alpha$ in sera of obese patients: fall with weight loss. J Clin Endocrinol Metab 1998;83:2907-10

Dandona P, Mohanty P, Ghanim H, Aljada A, Browne R, Hamouda W, Prabhala A, Afzal A, Garg R. The suppressive effect of dietary restriction and weight loss in the obese on the generation of reactive oxygen species by leukocytes, lipid peroxidation, and protein carbonylation. J Clin Endocrinol Metab 2001a;86:355-62

Dandona P, Aljada A, Mohanty P, Ghanim H, Hamouda W, Assian E, Ahmad S. Insulin inhibits intranuclear nuclear factor $\kappa B$ and stimulates $1 \kappa B$ in mononuclear cells in obese subjects: evidence for an anti-inflammatory effect? J Clin Endocrinol Metab 2001b;86:3257-65

Dandona P, Mohanty P, Hamouda W, Ghanim H, Aljada A, Garg R, Kumar V. Inhibitory effect of a two day fast on reactive oxygen species (ROS) generation by leucocytes and plasma ortho-tyrosine and meta-tyrosine concentrations. J Clin Endocrinol Metab 2001c;86:2899-902

de Lorgeril M, Renaud S, Mamelle N, Salen P, Martin JL, Monjaud I, Guidollet J, Touboul P, Delaye J. Mediterranean $\alpha$-linolenic acid-rich diet in secondary prevention of coronary heart disease. Lancet 1994;343:1454-9

Deopurkar R, Ghanim H, Friedman J, Abuaysheh S, Sia CL, Mohanty $P$, Vishwanathan $P$, Chaudhuri A, Dandona $P$ Differential effects of cream, glucose and orange juice on inflammation, endotoxin and the expression of toll like 
receptor-4 and suppressor of cytokine signaling-3. Diabetes Care 2010;Epub

Dhindsa S, Tripathy D, Mohanty P, Ghanim H, Syed T, Aljada $A$ and Dandona P. Differential effects of glucose and alcohol on reactive oxygen species generation and intranuclear nuclear factor- $\mathrm{KB}$ in mononuclear cells. Metabolism 2004; 53:330-4

Dolecek TA. Epidemiological evidence of relationships between dietary polyunsaturated fatty acids and mortality in the multiple risk factor intervention trial. Proc Soc Exp Biol Med 1992;200:177-82

Emanuelli B, Peraldi P, Filloux C, Chavey C, Freidinger K, Hilton DJ, Hotamisligil GS, Van Obberghen E. SOCS-3 inhibits insulin signaling and is up-regulated in response to tumor necrosis factor-alpha in the adipose tissue of obese mice. J Biol Chem 2001;276:47944-9

Fedor D, Kelley DS. Prevention of insulin resistance by n-3 polyunsaturated fatty acids. Curr Opin Clin Nutr Metab Care 2009;12:138-46

Festa A, D'Agostino R Jr, Howard G, Mykkanen L, Tracy RP, Haffner SM. Chronic subclinical inflammation as part of the insulin resistance syndrome: the Insulin Resistance Atherosclerosis Study (IRAS). Circulation 2000;102:42-7

Ghanim H, Aljada A, Hofmeyer D, Syed T, Mohanty P, Dandona P. Circulating mononuclear cells in the obese are in a proinflammatory state. Circulation 2004;110:1564-71

Ghanim H, Aljada A, Daoud N, Deopurkar R, Chaudhuri A, Dandona $P$. Role of inflammatory mediators in the suppression of insulin receptor phosphorylation in circulating mononuclear cells of obese subjects. Diabetologia 2007a;50:278-85

Ghanim H, Mohanty P, Pathak R, Chaudhuri A, Sia CL, Dandona $P$. Orange juice or fructose intake does not induce oxidative and inflammatory response. Diabetes Care 2007b; 30:1406-11

Ghanim H, Abuaysheh S, Sia CL, Korzeniewski K, Chaudhuri A, Fernandez-Real JM, Dandona P. Increase in Plasma Endotoxin Concentrations And The Expression of Toll Like Receptors And Suppressor of Cytokine Signaling-3 In Mononuclear Cells Following a High Fat High Carbohydrate Meal: Implications for Insulin Resistance. Diabetes Care 2009;32:2281-7

Gruppo Italiano per lo Studio della Sopravvivenza nell'Infarto miocardico. Dietary supplementation with $n-3$ polyunsaturated fatty acids and vitamin $E$ after myocardial infarction: results of the GISSI-Prevenzione trial. Lancet 1999;354: 447-55

Gual P, Le Marchand-Brustel Y, Tanti JF. Positive and negative regulation of insulin signaling through IRS-1 phosphorylation. Biochimie 2005;87:99-109

Harris WS, Windsor SL, Dujovne CA. Effects of four doses of $n-3$ fatty acids given to hyperlipidemic patients for six months. J Am Coll Nutr 1991;10:220-7

Hirosumi J, Tuncman G, Chang L, Gorgun CZ, Uysal KT, Maeda K, Karin M, Hotamisligil GS. A central role for JNK in obesity and insulin resistance. Nature 2002;420:333-6
Holub BJ. Dietary fish oils containing eicosapentaenoic acid and the prevention of atherosclerosis and thrombosis. CMAJ 1988;139:377-81

Hotamisligil GS, Shargill NS, Spiegelman BM. Adipose expression of tumor necrosis factor-alpha: direct role in obesity-linked insulin resistance. Science 1993;259:87-91

Hotamisligil GS, Peraldi P, Budavari A, Ellis R, White MF, Spiegelman BM. IRS-1-mediated inhibition of insulin receptor tyrosine kinase activity in TNF- $\alpha-$ and obesity-induced insulin resistance. Science 1996;271:665-8

Hu FB, Bronner L, Willett WC, Stampfer MJ, Rexrode KM, Albert CM, Hunter D, Manson JE. Fish and omega-3 fatty acid intake and risk of coronary heart disease in women. JAMA 2002;287:1815-21

James MJ, Gibson RA, Cleland LG. Dietary polyunsaturated fatty acids and inflammatory mediator production. Am J Clin Nutr 2000;71:343S-8S

Jenkins DJ, Josse AR, Dorian P, Burr ML, LaBelle Trangmar $\mathrm{R}$, Kendall CW, Cunnane SC. Heterogeneity in randomized controlled trials of long chain (fish) omega-3 fatty acids in restenosis, secondary prevention and ventricular arrhythmias. J Am Coll Nutr 2008;27:367-78

Kanda H, Tateya S, Tamori Y, Kotani K, Hiasa K, Kitazawa R, Kitazawa S, Miyachi H, Maeda S, Egashira K, Kasuga M. MCP-1 contributes to macrophage infiltration into adipose tissue, insulin resistance, and hepatic steatosis in obesity. J Clin Invest 2006;116:1494-505

Keenan JM, Pins JJ, Frazel C, Moran A, Turnquist L. Oat ingestion reduces systolic and diastolic blood pressure in patients with mild or borderline hypertension: a pilot trial. $J$ Fam Pract 2002;51:369

Kenny D, Warltier DC, Pleuss JA, Hoffmann RG, Goodfriend TL, Egan BM. Effect of omega-3 fatty acids on the vascular response to angiotensin in normotensive men. Am J Cardiol 1992; 70:1347-52

Kirby RW, Anderson JW, Sieling B, Rees ED, Chen WJ, Miller RE, Kay RM. Oat-bran intake selectively lowers serum low-density lipoprotein cholesterol concentrations of hypercholesterolemic men. Am J Clin Nutr 1981;34:824-9

Knapp HR. Dietary fatty acids in human thrombosis and hemostasis. Am J Clin Nutr 1997;65:1687S-1698S

Lairon D, Arnault N, Bertrais S, Planells R, Clero E, Hercberg $S$, Boutron-Ruault MC. Dietary fiber intake and risk factors for cardiovascular disease in French adults. Am J Clin Nutr 2005;82:1185-94

Lee JY, Zhao L, Youn HS, Weatherill AR, Tapping R, Feng L, Lee WH, Fitzgerald KA, Hwang DH. Saturated fatty acid activates but polyunsaturated fatty acid inhibits Toll-like receptor 2 dimerized with Toll-like receptor 6 or 1 . J Biol Chem 2004;279:16971-9

Lindstrom J, Peltonen M, Eriksson JG, Louheranta A, Fogelholm M, Uusitupa M, Tuomilehto J. High-fibre, low-fat diet predicts long-term weight loss and decreased type 2 diabetes risk: the Finnish Diabetes Prevention Study. Diabetologia 2006;49:912-20

Liu S, Stampfer MJ, Hu FB, Giovannucci E, Rimm E, Manson 
JE, Hennekens $\mathrm{CH}$, Willett WC. Whole-grain consumption and risk of coronary heart disease: results from the Nurses' Health Study. Am J Clin Nutr 1999;70:412-9

Martin RE. Docosahexaenoic acid decreases phospholipase A2 activity in the neurites/nerve growth cones of PC12 cells. J Neurosci Res 1998;54:805-13

Mente A, de Koning L, Shannon HS, Anand SS. A systematic review of the evidence supporting a causal link between dietary factors and coronary heart disease. Arch Intern Med 2009;169:659-69

Mohanty P, Hamouda W, Garg R, Aljada A, Ghanim H, Dandona P. Glucose challenge stimulates reactive oxygen species (ROS) generation by leucocytes. J Clin Endocrinol Metab 2000;85:2970-3

Mohanty P, Ghanim H, Hamouda W, Aljada A, Garg R, Dandona $P$. Both lipid and protein intakes stimulate increased generation of reactive oxygen species by polymorphonuclear leukocytes and mononuclear cells. Am J Clin Nutr 2002;75:767-72

Montonen J, Knekt P, Jarvinen R, Aromaa A, Reunanen A. Whole-grain and fiber intake and the incidence of type 2 diabetes. Am J Clin Nutr 2003;77:622-9

Morris MC, Sacks F, Rosner B. Does fish oil lower blood pressure? A meta-analysis of controlled trials. Circulation 1993;88:523-33

Mozaffarian D, Geelen A, Brouwer IA, Geleijnse JM, Zock PL, Katan MB. Effect of fish oil on heart rate in humans: a meta-analysis of randomized controlled trials. Circulation 2005;112:1945-52

Patel C, Ghanim H, Ravishankar S, Sia CL, Viswanathan P, Mohanty P, Dandona P. Prolonged reactive oxygen species generation and nuclear factor- $\kappa B$ activation after a high-fat, high-carbohydrate meal in the obese. J Clin Endocrinol Metab 2007;92:4476-9

Phillipson BE, Rothrock DW, Connor WE, Harris WS, Illingworth DR. Reduction of plasma lipids, lipoproteins, and apoproteins by dietary fish oils in patients with hypertriglyceridemia. N Engl J Med 1985;312:1210-6

Pickup JC, Mattock MB, Chusney GD, Burt D. NIDDM as a disease of the innate immune system: association of acute-phase reactants and interleukin- 6 with metabolic syndrome X. Diabetologia 1997;40:1286-92

Pradhan AD, Manson JE, Rifai N, Buring JE, Ridker PM. C-reactive protein, interleukin 6 , and risk of developing type 2 diabetes mellitus. JAMA 2001;286:327-34

Rodriguez BL, Sharp DS, Abbott RD, Burchfiel CM, Masaki $\mathrm{K}$, Chyou $\mathrm{PH}$, Huang B, Yano K, Curb JD. Fish intake may limit the increase in risk of coronary heart disease morbidity and mortality among heavy smokers. The Honolulu Heart Program. Circulation 1996;94:952-6

Rui L, Yuan M, Frantz D, Shoelson S, White MF. SOCS-1 and SOCS-3 block insulin signaling by ubiquitin-mediated degradation of IRS1 and IRS2. J Biol Chem 2002;277: 42394-8

Schenk S, Saberi M, Olefsky JM. Insulin sensitivity: modulation by nutrients and inflammation. J Clin Invest 2008; 118:2992-3002

Serhan CN, Chiang N, Van Dyke TE. Resolving inflammation: dual anti-inflammatory and pro-resolution lipid mediators. Nat Rev Immunol 2008;8:349-61

Steffen LM, Jacobs DR Jr, Stevens J, Shahar E, Carithers T, Folsom AR. Associations of whole-grain, refined-grain, and fruit and vegetable consumption with risks of all-cause mortality and incident coronary artery disease and ischemic stroke: the Atherosclerosis Risk in Communities (ARIC) Study. Am J Clin Nutr 2003;78:383-90

Streppel MT, Arends LR, van 't Veer P, Grobbee DE, Geleijnse JM. Dietary fiber and blood pressure: a meta-analysis of randomized placebo-controlled trials. Arch Intern Med 2005;165:150-6

Vuksan V, Sievenpiper JL, Owen R, Swilley JA, Spadafora $P$, Jenkins DJ, Vidgen E, Brighenti F, Josse RG, Leiter LA, Xu $Z$, Novokmet R. Beneficial effects of viscous dietary fiber from Konjac-mannan in subjects with the insulin resistance syndrome: results of a controlled metabolic trial. Diabetes Care 2000;23:9-14

Wang S, Leonard SS, Castranova V, Vallyathan V, Shi X. The role of superoxide radical in TNF-alpha induced NF- $\mathrm{KB}$ activation. Ann Clin Lab Sci 1999;29:192-9

Wannamethee SG, Whincup PH, Thomas MC, Sattar N. Associations between dietary fiber and inflammation, hepatic function, and risk of type 2 diabetes in older men: potential mechanisms for the benefits of fiber on diabetes risk. Diabetes Care 2009;32:1823-5

Whelton SP, Hyre AD, Pedersen B, Yi Y, Whelton PK, He J. Effect of dietary fiber intake on blood pressure: a meta-analysis of randomized, controlled clinical trials. J Hypertens 2005;23:475-81

Woodfin A, Voisin MB, Nourshargh S. PECAM-1: a multi-functional molecule in inflammation and vascular biology. Arterioscler Thromb Vasc Biol 2007;27:2514-23

Woronicz JD, Gao X, Cao Z, Rothe M, Goeddel DV. IkappaB kinase-beta: NF-kappaB activation and complex formation with IKB kinase-alpha and NIK. Science 1997;278: 866-9.

Wright RS, Anderson JW, Bridges SR. Propionate inhibits hepatocyte lipid synthesis. Proc Soc Exp Biol Med 1990; 195:26-9

Yokoyama M, Origasa H, Matsuzaki M, Matsuzawa Y, Saito Y, Ishikawa Y, Oikawa S, Sasaki J, Hishida H, Itakura H, Kita T, Kitabatake A, Nakaya N, Sakata T, Shimada K, Shirato K. Effects of eicosapentaenoic acid on major coronary events in hypercholesterolaemic patients (JELIS): a randomised open-label, blinded endpoint analysis. Lancet 2007;369: 1090-8 